\title{
Functional Connectivity within the Primate Extended Amygdala Is Heritable and Associated with Early-Life Anxious Temperament
}

\author{
(1DAndrew S. Fox, ${ }^{2 *}$ - Jonathan A. Oler, ${ }^{1 \star}$ Rasmus M. Birn, ${ }^{1,3}$ ๑Alexander J. Shackman, ${ }^{4}$ Andrew L. Alexander, ${ }^{1,3}$ \\ and Ned H. Kalin ${ }^{1,5}$ \\ ${ }^{1}$ Department of Psychiatry, University of Wisconsin School of Medicine and Public Health, Madison, Wisconsin 53719, ${ }^{2}$ Department of Psychology and \\ California National Primate Research Center, University of California, Davis, California 95616, ${ }^{3}$ Department of Medical Physics, University of Wisconsin, \\ Madison, Wisconsin 53705, ${ }^{4}$ Department of Psychology, Maryland Neuroimaging Center, and Neuroscience and Cognitive Science Program, University of \\ Maryland, College Park, Maryland 20742, and ${ }^{5}$ Wisconsin National Primate Research Center, Madison, Wisconsin 53715
}

Children with an extremely inhibited, anxious temperament (AT) are at increased risk for anxiety disorders and depression. Using a rhesus monkey model of early-life AT, we previously demonstrated that metabolism in the central extended amygdala (EAc), including the central nucleus of the amygdala (Ce) and bed nucleus of the stria terminalis (BST), is associated with trait-like variation in AT. Here, we use fMRI to examine relationships between Ce-BST functional connectivity and AT in a large multigenerational family pedigree of rhesus monkeys ( $n=170$ females and 208 males). Results demonstrate that Ce-BST functional connectivity is heritable, accounts for a significant but modest portion of the variance in AT, and is coheritable with AT. Interestingly, Ce-BST functional connectivity and AT-related BST metabolism were not correlated and accounted for non-overlapping variance in AT. Exploratory analyses suggest that Ce-BST functional connectivity is associated with metabolism in the hypothalamus and periaqueductal gray. Together, these results suggest the importance of coordinated function within the EAc for determining individual differences in AT and metabolism in brain regions associated with its behavioral and neuroendocrine components.

Key words: amygdala; anxiety; bed nucleus of the stria terminalis; fMRI; heritability; rhesus monkey

Significance Statement

Anxiety disorders directly impact the lives of nearly one in five people, accounting for substantial worldwide suffering and disability. Here, we use a nonhuman primate model of anxious temperament (AT) to understand the neurobiology underlying the early-life risk to develop anxiety disorders. Leveraging the same kinds of neuroimaging measures routinely used in human studies, we demonstrate that coordinated activation between the central nucleus of the amygdala and the bed nucleus of the stria terminalis is correlated with, and coinherited with, early-life AT. Understanding how these central extended amygdala regions work together to produce extreme anxiety provides a neural target for early-life interventions with the promise of preventing lifelong disability in at-risk children.

\section{Introduction}

Behavioral inhibition and anxious temperament (AT) are related temperamental dimensions that are apparent early in life and, when extreme, confer increased risk for the development of anxiety disorders and other stress-related psychopathology (N. A. Fox et al., 2005; Clauss and Blackford, 2012; Fox and Kalin, 2014). 
To investigate the neurogenetic mechanisms underlying earlylife risk, we developed and characterized a nonhuman primate (NHP) model of AT (Fox and Kalin, 2014; Kalin, 2017). Mechanistic and imaging work by our group highlights the importance of the central extended amygdala (EAc), including the central nucleus of the amygdala $(\mathrm{Ce})$ and the bed nucleus of the stria terminalis (BST), for trait-like variation in the AT (A. S. Fox et al., 2005, 2008, 2015b; Kalin et al., 2005; Oler et al., 2010). These EAc regions are considered to be a macrostructural anatomical unit based on similarities in cell types, robust structural and functional connectivity, and similar projections to downstream effector regions (Heimer and Van Hoesen, 2006; Oler et al., 2012, 2017; A. S. Fox et al., 2015a; Shackman et al., 2017; Tillman et al., 2018). Preclinical and clinical studies have implicated the EAc in adaptive and maladaptive fear and anxiety behavior (Avery et al., 2016; Gungor and Paré, 2016; Shackman and Fox, 2016), and the EAc is well positioned to orchestrate the extreme threat responses that are characteristic of anxiety and depressive disorders (Shackman et al., 2016b; Fox and Shackman, 2017). Here, we examine the intrinsic functional connectivity of the Ce and the BST and assess whether EAc interconnectivity is heritable and genetically correlated with AT.

NHP AT is based on assessing individual differences in behavioral inhibition and accompanying pituitary-adrenal activation when young monkeys are confronted with a potential threat in the no-eye-contact condition (NEC) of the human intruder paradigm (Kalin and Shelton, 1989; Fox et al., 2008). During NEC, the monkey is exposed to the profile of a human intruder ensuring that there is not eye contact between the intruder and the monkey. The uncertain threat associated with the lack of eye contact typically results in increased freezing, decreased vocalizations, and increased cortisol (Kalin et al., 1998; A. S. Fox et al., 2005, 2008, 2015b; Jahn et al., 2010; Oler et al., 2010; Shackman et al., 2013). These responses parallel those of behaviorally inhibited children exposed to unfamiliar adults (Kagan et al., 1987, 1988; Oler et al., 2016). Based on this, we defined AT as a composite measure of monkeys' NEC-induced behavioral and cortisol responses, and extensive studies have demonstrated the reliability and validity of this measure (Kalin and Shelton, 2003; A. S. Fox et al., 2008, 2015b; Fox and Kalin, 2014; Kalin, 2017). Similar to heritability estimates for early-life anxiety and behavioral inhibition (Emde et al., 1992; Eley et al., 2003), our measure of early-life AT is $\sim 30 \%$ heritable.

In a series of ${ }^{18} \mathrm{~F}$-fluorodeoxyglucose $\left({ }^{18} \mathrm{FDG}\right)$ positron emission tomography (FDG-PET) imaging studies, we demonstrated that Ce and BST metabolism both predict individual differences in AT (Kalin et al., 2005; Fox et al., 2008, 2015b; Oler et al., 2010). We also mechanistically linked the Ce to AT, as we found that Ce lesions decrease threat-related freezing behavior and pituitaryadrenal activation (Kalin et al., 2004). Interestingly, we observed individual differences in BST metabolism, but not Ce metabolism, to be genetically correlated with AT, suggesting that structural genetic alterations influence AT by exerting their effects on BST metabolism (A. S. Fox et al., 2015b). Because of the causal role of Ce in giving rise to the expression of AT (Kalin et al., 2004, 2016), along with the previously observed strong functional and structural connectivity between Ce and BST (Oler et al., 2012, 2017), the AT-predictive nature of heritable glucose metabolism (FDG-PET) in the BST (Fox et al., 2015b), and the theorized role for EAc in anxiety (A. S. Fox et al., 2015a), we hypothesized that individual differences in Ce-BST connectivity would be heritable and would correlate with individual differences in BST metabolism and the expression of AT.
Here, we examined the coordinated function between the Ce and BST in relation to AT using intrinsic functional connectivity in a large sample of young rhesus monkeys $(n=378)$ belonging to a well characterized, large multigenerational pedigree. We also performed analyses to understand the extent to which individual differences in Ce-BST functional connectivity are heritable and how this heritability relates to the heritability of AT.

\section{Materials and Methods}

Except where noted otherwise, behavioral and brain imaging methods have been described in detail in prior publications (Oler et al., 2012; Birn et al., 2014; A. S. Fox et al., 2015b) and are only briefly summarized here.

Subjects. As part of a larger program of research focused on the mechanisms underlying extreme early-life anxiety, we attempted to test every young rhesus monkey (Macaca mulatta) that was available for study at the Harlow Center for Biological Psychology or the Wisconsin National Primate Research Center over a multiyear period (2007-2011). Animal availability determined the final sample size. Individuals that underwent prior studies involving drug administration, surgery, or intensive behavioral testing were excluded. As detailed by A. S. Fox et al. (2015b), imaging (FDG-PET, fMRI), phenotypic (AT), and demographic data were acquired from 594 young rhesus monkeys. Subjects were members of an extended, multigenerational pedigree (1928 individuals; eight generations; 2 parent-offspring pairs; 28 full-sibling pairs; 44 other first-degree pairs; 11 avuncular pairs; 1340 half-sibling pairs; 1388 other seconddegree pairs; 3293 third-degree pairs; 6991 fourth-degree pairs; 73,138 more than fourth-degree pairs; and 83,419 unrelated pairs). Two animals with questionable paternity were excluded from all analyses [mean (M), 1.88 years; standard deviation (SD), 0.78; 327 males/265 females]. As detailed below, high-quality fMRI data were available for a subset of 378 individuals (M, 1.84 years; SD, 0.76; 208 males and 170 females). Of the 378 animals with data included in this analysis, 288 were scanned at the HealthEmotions Research Institute in the Department of Psychiatry, whereas 90 animals were scanned at the Waisman Laboratory for Brain Imaging and Behavior. These individuals represent a superset of the sample previously described by Birn et al. (2014) and Oler et al. (2012, 2017). Both samples can be considered preadolescent, as rhesus macaques are typically weaned between 6 and 12 months and become sexually mature between 3 and 4 years of age (Rawlins and Kessler, 1986). Monkeys were mother reared, pair housed, and maintained on a $12 \mathrm{~h}$ light/dark cycle. All data were acquired during the light cycle. All procedures were approved by and in accordance with the guidelines established by the Institutional Animal Care and Use Committee.

Quantifying individual differences in the AT phenotype. Individual differences in the AT composite phenotype were quantified using the 30 min NEC condition of the human intruder paradigm (Kalin and Shelton, 1989; Kalin, 1993; Fox et al., 2008). Subjects were placed in a standard testing cage. An experimenter entered the room and stood motionless $\sim 2.5 \mathrm{~m}$ from the subject while presenting his profile and avoiding direct eye contact. Subjects were allowed to freely respond to this ethologically relevant potential threat, similar to procedures used to assess dispositional anxiety and behavioral inhibition in children (Kagan et al., 1988; Kagan, 1997; N. A. Fox et al., 2005). Anxiety-related behaviors elicited by the NEC challenge were unobtrusively quantified by an experienced observer blind to pedigree status using a closed-circuit audiovisual system. Freezing was defined as a period of $>3 \mathrm{~s}$ characterized by a tense body posture and the absence of vocalizations or movements other than slow head movements or eye blinks. "Coo" vocalizations were defined as audible calls characterized by an increase and then a decrease in frequency and intensity made by rounding and pursing the lips. Coo calls are contact or separation vocalizations that are elicited by exposure to the test cage (i.e., the "alone" condition of the human intruder paradigm) and suppressed by exposure to the NEC challenge (i.e., human intruder's profile; Kalin and Shelton, 1989, 1998; Bauers and de Waal, 1991; A. S. Fox et al., 2005). After behavioral testing, blood was collected for quantifying cortisol. Plasma cortisol (in micrograms per deciliter) was quantified in duplicate using the DPC Coat-a-count radioimmunoassay (Siemens). The assay had an interassay coefficient of variation $(\mathrm{CV} \%)$ of 
7.0 and an intra-assay CV\% of 4.0 and a lower limit of detection, defined as the lowest standard included in the assay, of $1 \mu \mathrm{g} / \mathrm{dl}$. Mean freezing duration and cooing frequency were $\log _{e}$ and square root transformed, respectively. Standardized cortisol, freezing, and vocalization measures were created by linearly removing nuisance variance in age, and in the case of cortisol, time of day. The composite AT phenotype was computed as the arithmetic mean of standardized cortisol, freezing, and vocalization; vocalizations were first inverted $(-1 \times$ standardized coo frequency) to ensure that larger values indicated increased reactivity to the NEC challenge.

MRI acquisition. Structural and functional MRI data were collected under anesthesia using a General Electric Signa 3T scanner (GE Medical Systems) equipped with a standard $16 \mathrm{~cm}$ quadrature extremity coil. Subjects were anesthetized with ketamine $(15 \mathrm{mg} / \mathrm{kg}, \mathrm{i} . \mathrm{m}$.), placed in a stereotactic head frame, and positioned in the scanner. Immediately before the start of the first scan, subjects received medetomidine $(30 \mu \mathrm{g} / \mathrm{kg}$, i.m.) or dexmedetomidine ( $15 \mu \mathrm{g} / \mathrm{kg}$, i.m.). Small booster doses of ketamine were administered as needed to maintain anesthesia $(<15 \mathrm{mg} / \mathrm{kg}$, i.m.). Heart rate and oxygen saturation were monitored using a pulse oximeter. Anatomical scans were obtained with a 3D T1-weighted, inversion-recovery, fast gradient echo prescription (TI, $600 \mathrm{~ms}$; TR, 8.65 ms; TE, $1.89 \mathrm{~ms}$; flip angle, $10^{\circ}$; NEX, 2; FOV, $140 \mathrm{~mm}$; matrix, $256 \times$ 224; bandwidth, $61.1 \mathrm{kHz}$ ) with whole-brain coverage (128 slice encodes over $128 \mathrm{~mm}$ ) reconstructed with zero-filled interpolation to $0.27 \times$ $0.27 \times 0.5 \mathrm{~mm}$ on the scanner. Functional scans were obtained using a $2 \mathrm{D} \mathrm{T} 2{ }^{*}$-weighted echoplanar image (EPI) prescription (TR, $2500 \mathrm{~ms}$; TE, $25 \mathrm{~ms}$; flip angle, $90^{\circ}$; FOV, $140 \mathrm{~mm}$; matrix, $64 \times 64 ; 26 \times 3.1 \mathrm{~mm}$ axial slices; gap, $0.5 \mathrm{~mm}$; 360 volumes). At the conclusion of the scan, the medetomidine or dexmedetomidine was reversed with atipamezole (150 $\mu \mathrm{g} / \mathrm{kg}$, i.m.).

PET acquisition. Subjects received an intravenous injection of ${ }^{18} \mathrm{FDG}$ immediately before the $30 \mathrm{~min}$ NEC challenge. Immediately after the NEC challenge, subjects were deeply anesthetized $(15 \mathrm{mg} / \mathrm{kg}$ ketamine, i.m.), intubated, and positioned in a stereotactic device within the Siemens/Concorde microPET P4 scanner (Tai et al., 2001). Both FDG and attenuation scans were acquired. FDG-PET, which provides a measure of regional brain metabolism integrated over the entire $30 \mathrm{~min}$ behavioral challenge, is ideally suited for assessing trait-like individual differences in neural activity. During the PET scan, anesthesia was maintained using $1-2 \%$ isoflurane gas. Images were reconstructed using standard filteredbackprojection techniques with attenuation and scatter correction.

MRI/PET data processing pipeline. EPI data were processed using standard techniques in AFNI (http://afni.nimh.nih.gov; Cox, 1996) except where noted otherwise. The initial three time points were removed, and data were processed to attenuate motion artifact ( $6 \mathrm{df}$ ), $\mathrm{B}_{0}$-field distortions, physiological noise (Glover et al., 2000), and slice-timing differences.

To minimize normalization error (Fein et al., 2006; Acosta-Cabronero et al., 2008; Fischmeister et al., 2013), brains were manually extracted from T1 images using SPAMALIZE (https://idoimaging.com/programs/ 275). Native-space, brain-extracted T1 images were normalized to the study-specific template described by Fox et al. (2015b) using Advanced Normalization Tools (Avants et al., 2010, 2011). Each native-space FDGPET image was aligned to its corresponding $\mathrm{T} 1$ image using a rigid-body mutual information warp. The resulting transformation matrix was concatenated with that defining the diffeomorphic transformation to the template and used to spatially normalize the PET images. Normalized PET images were global-mean scaled within the brain using SPAMALIZE. Scaled PET maps were spatially smoothed ( $2 \mathrm{~mm}$ FWHM Gaussian). Single-subject, native-space, brain-extracted T1 images were linearly registered to the corresponding EPI images, allowing only for shifts within the coronal plane (Saad et al., 2009). The resulting transformation matrix was reversed, concatenated with the diffeomorphic transformation matrix, and used to normalize the EPI data to the studyspecific template (interpolated to $0.625 \mathrm{~mm}^{3}$ ). All images were carefully inspected for quality assurance purposes.

To further attenuate physiological noise, average white matter (WM) and ventricular (CSF) time series and their temporal derivatives were residualized from the EPI time series (Jo et al., 2010). WM and CSF regions were identified by thresholding segmented $\mathrm{T} 1$ images. To minimize contributions from adjacent gray matter regions, WM was eroded by 2 voxels and CSF was limited to the lateral ventricles by multiplying single-subject CSF regions by a template-defined mask. Artifact-attenuated EPI data were spatially ( $4 \mathrm{~mm}$ FWHM Gaussian) and temporally (0.008$0.08 \mathrm{~Hz}$ ) filtered. We visually verified that all datasets showed adequate EPI coverage without excess susceptibility or distortion artifacts (e.g., signal shearing or compression). Quantitatively, we verified that all datasets showed an adequate temporal signal-to-noise ratio $(>100)$ in regions vulnerable to susceptibility artifacts (e.g., orbitofrontal and medial temporal cortices; Parrish et al., 2000; LaBar et al., 2001). Individual EPI volumes with $>1 \mathrm{~mm}$ of volume-to-volume motion were censored.

Ce seed. The amygdala is a complex structure, composed of numerous anatomically and physiologically distinct nuclei (Amaral et al., 1992; Freese and Amaral, 2009). Here, we used previously published in vivo serotonin transporter (5-HTT) binding data (Christian et al., 2009) to objectively define the Ce nucleus. Ex vivo research demonstrates that the lateral division of the primate Ce expresses substantially higher 5-HTT levels compared with neighboring regions of the medial temporal lobe (O'Rourke and Fudge, 2006). Capitalizing on this chemoarchitectonic signature, we used the distribution of ${ }^{11} \mathrm{C}$-DASB (a high-affinity radiolabeled 5-HTT ligand) in an independent sample of 34 young monkeys to probabilistically define the Ce seed [for similar mapping applications and detailed methods, see Oler et al. (2012, 2017) and A. S. Fox et al. (2015b)]. Briefly, dynamic PET time series were transformed into voxelwise maps of the distribution volume ratio (DVR; an index of receptor availability) normalized to activity in a cerebellar reference region. Single-subject DVR maps were normalized to the study-specific template using ANTS and averaged. The resulting probabilistic (i.e., mean) 5-HTT binding map was thresholded ( $250 \times$ cerebellum) to define the Ce seed used for fMRI analyses.

Quantifying heritability and coheritability. Voxelwise heritability analyses were performed using SOLAR (http://solar-eclipse-genetics.org; Almasy and Blangero, 1998), using pedigree information curated by Dr. Jeff Rogers (Baylor College of Medicine and Wisconsin National Primate Research Center, Madison, WI). Heritability was computed as described by A. S. Fox et al. (2015b) and is only summarized here. Because the initial step in the heritability analysis uses the inverse normal distribution of the trait being examined, the heritability of Ce functional connectivity was estimated using voxelwise fMRI $\beta$ weights rather than the normalized Fisher's $z$ coefficients. We first computed the trait's covariance matrix as well as a relatedness matrix, which can be computed based on each pair of animals' relationship to each other in the pedigree (e.g., monozygotic twin pairs, 1.0; parent-offspring pairs, 0.50; half-sibling pairs, 0.25). Using the covariance and relatedness matrices, we estimated the genetic and environmental variance of a quantitative phenotypic trait (e.g., voxelwise functional connectivity). The variance attributed to the environment is considered to be random for each subject and not shared between subjects. Heritability $\left(h^{2}\right)$ can be estimated based on the variance in genetic and environmental effects, and the probability of $h^{2}$ is computed by comparing the log likelihood of the model and the difference between this model and another where the variance estimate associated with the trait of interest (i.e., Ce connectivity) is constrained to equal zero. To assess the genetic correlation $\left(\rho_{\mathrm{G}}\right)$ between functional connectivity and AT, bivariate heritability (i.e., coheritability) analyses were performed using a similar approach with a covariance matrix representing both quantitative traits (functional connectivity and AT) and their interaction. This analysis examines the extent to which estimated genetic covariation is associated with covariation among phenotypes and estimates that the proportion of variance two traits share is attributable to genetic causes. For a detailed description, see the studies by Almasy et al. (1997), Almasy and Blangero (1998), Williams et al. (1999), and A. S. Fox et al. (2015b).

Experimental design and statistical analysis. As detailed above, FDGPET, phenotypic (AT), demographic, and pedigree data were available for 592 individuals and fMRI data were available for a subset of 378 individuals, enabling us to compute sufficiently stable effect-size estimates (Schönbrodt and Perugini, 2013). Given our aims, we adopted a standard a priori seed-based approach to quantifying intrinsic functional 
A

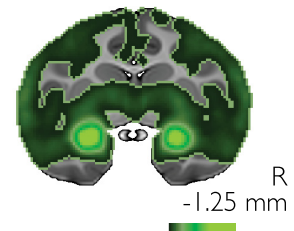

t-value of main effect of Ce connectivity

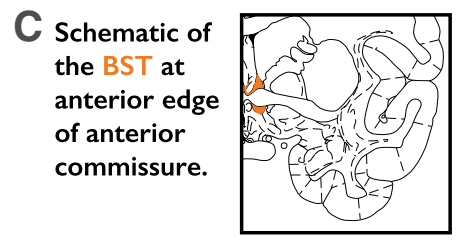

B
Main effect of intrinsic fMRI connectivity with Ce ( $\mathrm{p}<.05$, Šidák corrected, two-tailed)

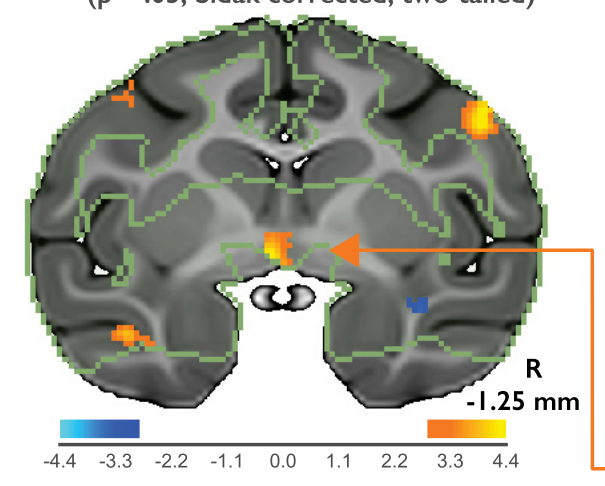

$\mathrm{t}$-value of AT-related intrinsic $\mathrm{PMRI}$ connectivity with $\mathrm{Ce}$ ( $p<.005$, uncorrected, two-tailed)

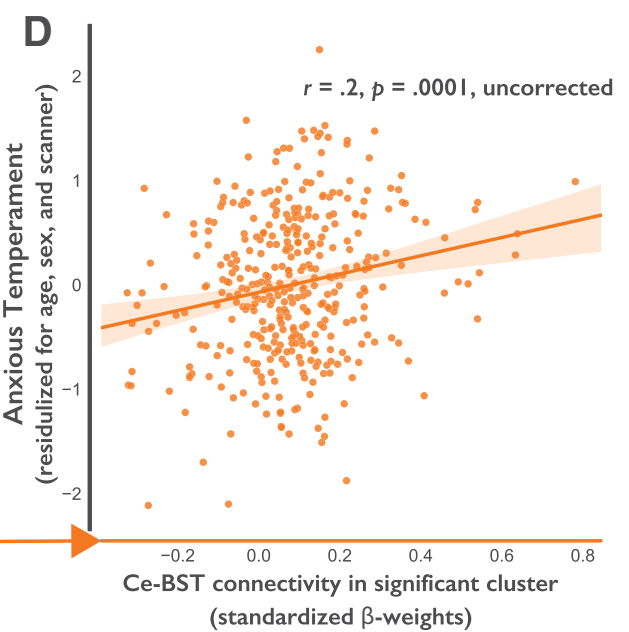

(standardized $\beta$-weights)

Figure 1. AT-related (e functional connectivity. A, Regions showing significant intrinsic functional connectivity with the bilateral Ce seed are depicted in green (Šidák corrected, $n=378$ ). Note the robust correlations in the vicinity of the bilateral Ce seeds. B, Stronger functional connectivity between the Ce and the BST (orange arrow) is associated with higher levels of AT ( $p<0.005$, uncorrected). Voxelwise analyses were restricted to regions showing significant functional connectivity with the Ce, as indicated by the green outline. C, BST in the rhesus atlas (Paxinos et al., 2009). D, Relationships between Ce-BST connectivity and AT. The scatterplot is shown for illustrative purposes only.

connectivity. For each subject, we used AFNI to perform a voxelwise correlation between the artifact-attenuated EPI time series, averaged across the voxels defining the Ce seed, and voxel time series throughout the brain. Correlation maps were normalized (Fisher's $R$-to- $Z$ transformation) and used to identify regions with consistent functional connectivity across subjects. This was done by testing the intercept in a regression model controlling for mean-centered age and sex, equivalent to a single-sample $t$ test. As in prior work by our group, the resulting map of Ce functional connectivity was conservatively thresholded $(p<0.05$, whole-brain Šidák corrected). Next, we used a regression analysis to examine relationships between Ce functional connectivity and individual differences in AT in regions where Ce connectivity was statistically significant. The resulting map was thresholded at $p=0.005$ (uncorrected).

Voxelwise heritability and coheritability were calculated using SOLAR (using resources provided by the University of Wisconsin-Madison Center for High-Throughput Computing) and controlling for the influence of age, age ${ }^{2}$, sex, and the age $\times$ sex interaction. Voxelwise heritability analyses were restricted to regions demonstrating significant functional connectivity with the Ce seed and a significant correlation with AT (see Fig. 2, orange outline). Heritability values at each voxel were extracted, and a series of two-sample Kolmogorov-Smirnov (KS) tests were used to rigorously test whether the distribution of heritability estimates for CeBST functional connectivity differed from (1) the set of voxels where Ce functional connectivity was significant and significantly associated with individual differences in AT, (2) the larger set of voxels where Ce functional connectivity was significant, and (3) all voxels in the brain.

On an exploratory basis, we also examined voxelwise relationships between AT-related Ce-BST functional connectivity and individual differences in AT-related metabolic activity. To this end, each subject's normalized functional connectivity coefficients were extracted from the BST region demonstrating significant AT-related functional connectivity with the Ce (Fig. 1, BST cluster). The mean connectivity coefficient for each subject was then used to predict voxelwise FDG metabolism. This exploratory analysis was restricted to regions demonstrating significant AT-related glucose metabolism (A. S. Fox et al., 2015b; see Fig. 4, pink outline) and thresholded at $p<0.01$ (uncorrected). Finally, mediation analyses were performed using the statsmodels mediation analysis tool (statsmodels.stats.mediation, version 0.8.0) to test the extent to which FDG-PET significantly accounted for the relationship between Ce functional connectivity and AT (Imai et al., 2010; Tingley et al., 2014).

\section{Results}

In 378 anesthetized monkeys, spontaneous fluctuations in the Ce BOLD signal were highly significantly correlated with BOLD sig- nal fluctuations within three clusters identified using a stringent Šidák-level statistical threshold $(t>5.4131$, Šidák $p<0.05$, equivalent to a $p=0.00000005522$, uncorrected; minimum cluster size, $\geq 250$ voxels). The three clusters included a large cluster $\left(>26,264 \mathrm{~mm}^{3}\right)$ that was positively connected with Ce and encompassed numerous brain regions and two smaller bilateral clusters in the posterior dorsal thalamus (left, $264 \mathrm{~mm}^{3}$; right, $254 \mathrm{~mm}^{3}$ ), which were negatively coupled to the Ce. Consistent with prior work in monkeys (Oler et al., 2012, 2017; Birn et al., 2014) and humans (Oler et al., 2012; Gorka et al., 2017; Tillman et al., 2018; Torrisi et al., 2018), one of the highest extra-amygdala peaks was observed in the BST region. The large positively connected cluster of the Šidák-corrected connectivity map also included dorsolateral and ventromedial portions of the prefrontal cortex, orbital proisocortex/anterior insula, temporal pole, ventral striatum, portions of the superior temporal sulcus, premotor cortex, anterior cingulate cortex, dorsal midcingulate cortex, posterior cingulate cortex, and various regions of the visual cortex including V1 (Fig. 1A).

We next examined the correlation between Ce connectivity and AT by running a voxelwise regression while controlling for several nuisance variables (including age, sex, housing location, MRI scanner location, and the number of prior exposures to NEC). Voxelwise analyses were restricted to regions within the Šidák-corrected Ce connectivity mask (Fig. 1B, green outline), reducing the number of comparisons and circumventing the need to interpret associations in regions that do not show evidence of significant Ce connectivity [for a similar approach, see Tillman et al. (2018)]. Although no regions survived False Detection Rate (FDR) correction, when a more lenient threshold was applied ( $p<0.005$, uncorrected), stronger Ce connectivity was associated with higher levels of AT in several regions, including the BST (Fig. 1B, Table 1). Control analyses indicated that neither the "main effect" of Ce-BST connectivity nor the association between Ce-BST connectivity and AT was influenced by sex $(t<$ $1.14 ; p>0.25)$.

We previously demonstrated that individual differences in AT are 29\% heritable (A. S. Fox et al., 2015b), consistent with work focused on behavioral inhibition (BI), trait anxiety, and anxiety disorders (DiLalla et al., 1994; Hettema et al., 2005; Hirshfeld- 
Table 1. Descriptive statistics for clusters showing significant Ce functional connectivity and significant associations with AT

\begin{tabular}{|c|c|c|c|c|c|c|c|c|c|}
\hline \multirow[b]{2}{*}{ Sign } & \multirow[b]{2}{*}{ Hemisphere } & \multirow[b]{2}{*}{ Cluster } & \multirow[b]{2}{*}{ Volume $\left(\mathrm{mm}^{3}\right)$} & \multirow[b]{2}{*}{ Local maxima } & \multirow[b]{2}{*}{$t_{\mathrm{Max}}^{a}$} & \multirow[b]{2}{*}{$p$} & \multicolumn{3}{|c|}{ Location (mm from AC) } \\
\hline & & & & & & & $x$ & $y$ & $z$ \\
\hline \multirow[t]{3}{*}{ Positive } & Right & Premotor cortex & 63.72 & Area 6 & 4.27 & $<0.0001$ & 21.875 & -0.625 & -11.250 \\
\hline & Left & Basal forebrain & 34.67 & BST & 4.17 & $<0.0001$ & -1.875 & -0.625 & -3.125 \\
\hline & Left & Premotor cortex & 12.70 & Area 6 & 3.56 & 0.0002 & -18.750 & 0.000 & 13.125 \\
\hline Negative & Right & Superior temporal sulcus & 28.56 & Fundus & -3.65 & 0.0002 & 15.625 & 0.000 & -7.500 \\
\hline
\end{tabular}

${ }^{a}$ Voxelwise regression controlling for nuisance variation in age, sex, housing location, MRI scanner location, and the number of prior exposures to NEC $\left(p<0.005\right.$, uncorrected, two-tailed, minimum cluster size of 7 mm $\left.{ }^{3}\right)$. The regression was restricted to voxels showing significant intrinsic functional connectivity with the $\mathrm{Ce}(p<0.05$, whole-brain Šidák corrected). TEa, temporal area TEa; IPa, intraparietal sulcus associated area in the superior temporal sulcus.

A Histogram of voxelwise heritablity in regions with AT-related connectivity reveals enriched heritability in BST

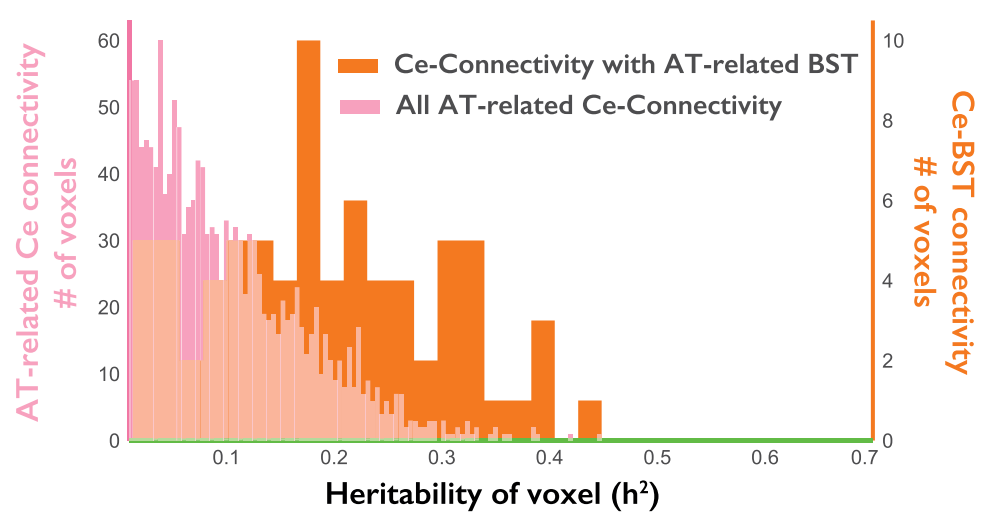

B Voxelwise search for significantlty heritable AT-related voxels

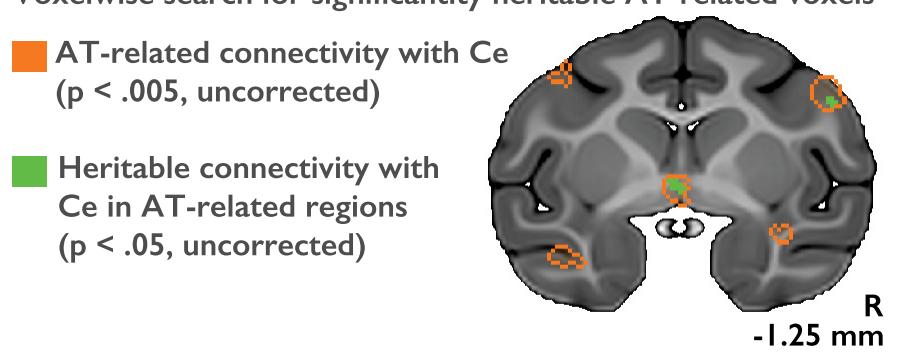

Figure 2. Individual differences in Ce-BST functional connectivity are heritable. $\boldsymbol{A}$, Voxelwise heritability of Ce functional connectivity. Pink bars (left axis) indicate the distribution of heritability estimates across all voxels demonstrating both significant functional connectivity with the $\mathrm{Ce}(p<0.05$, Šidák corrected) and a significant relationship with individual differences in AT $(p<0.005$, uncorrected). Orange bars (right axis) indicate the distribution of heritability estimates across the voxels located within the BST cluster that satisfied these two criteria. Heritability of Ce connectivity is significantly greater in the BST when compared with the Ce connectivity values from all AT-related voxels in the brain (two-sample Kolmogorov-Smirnov test, 0.43 , $p<0.001)$. B For illustrative purposes, voxels showing significant heritability ( $p<0.05$, uncorrected) are depicted (green). Regions demonstrating both significant functional connectivity with the Ce and a significant relationship with individual differences in AT are outlined in orange.

Becker et al., 2008; Geschwind and Flint, 2015). A. S. Fox et al. (2015b) subsequently showed that BST metabolism is both heritable and genetically correlated with AT; that is, they show similar patterns of intergenerational transmission. Here, we used the available pedigree information to estimate the voxelwise heritability of Ce functional connectivity for the first time. Across the entire brain, AT-related Ce functional connectivity was modestly heritable (Fig. $2 A$, pink bars), with the peak heritability estimate $\left(h^{2}=0.45\right)$ in the same region of BST where Ce-BST connectivity was both significant and significantly associated with individual differences in AT (Fig. $2 \mathrm{~A}$, orange bars). Voxelwise heritability estimates in regions where Ce connectivity was significant and significantly associated with AT are presented in Figure $2 B$ and Table 2.
To determine whether the heritability of Ce-BST connectivity was significantly different from the heritability of overall AT-related Ce connectivity, we ran a two-sample Kolmogorov-Smirnov test to examine whether the distribution of heritability estimates for the Ce connectivity values from all AT-related voxels in the brain (Fig. 2A, pink bars) differed from the distribution of heritability estimates for the AT-related Ce connectivity values in voxels within BST (Fig. $2 A$, orange bars). The results demonstrated that the distribution of heritability estimates in the BST significantly differed from the distribution of heritability estimates for all other AT-related, Ce-connected voxels in the brain (KS test, $0.43 ; p<0.001$ ). This was also true when testing whether the heritability estimates of AT-related Ce connectivity values in BST voxels differed from those in all voxels showing significant Ce connectivity (KS test, $0.43 ; p<$ 0.001), as well as when testing the BST voxels versus all voxels in the brain (KS test, $0.43 ; p<0.001$ ).

Together, this pattern of results raises the possibility that Ce-BST connectivity is associated with the intergenerational transmission of AT from parents to their offspring. To formally test the hypothesis that AT shares a genetic substrate with Ce-BST connectivity, as it does with BST metabolism, we estimated the genetic correlation between individual differences in AT and functional connectivity in the region of BST identified by the heritability analyses (Fig. 2B, green voxels in the center). Results revealed that Ce-BST connectivity and AT are significantly genetically correlated $\left(\rho_{\mathrm{g}}=0.874 ; p<0.05\right)$, suggesting that the genes underlying variation in Ce-BST connectivity likely play a role in AT.

When considered with our previous demonstration that AT is genetically correlated with BST metabolism (A. S. Fox et al., 2015b), these data raise the possibility that there is a common pathway through which AT is influenced by genes that alter CeBST connectivity, leading to altered BST metabolism, and ultimately change AT. To directly test this hypothesis, we extracted Ce-BST functional connectivity from each of the 378 animals (Fig. 3, left). Next, we extracted AT-related metabolic activity (FDG-PET signal) from the same individuals using the BST clus- 
Table 2. Descriptive statistics for clusters showing significant Ce functional connectivity, significant associations with AT, and significant heritability

\begin{tabular}{|c|c|c|c|c|c|c|c|c|}
\hline \multirow[b]{2}{*}{ Hemisphere } & \multirow[b]{2}{*}{ Cluster } & \multirow[b]{2}{*}{ Volume $\left(\mathrm{mm}^{3}\right)$} & \multirow[b]{2}{*}{ Local maxima } & \multirow[b]{2}{*}{$h^{2}$} & \multirow[b]{2}{*}{$p$} & \multicolumn{3}{|c|}{ Location (mm from AC) } \\
\hline & & & & & & $x$ & $y$ & $z$ \\
\hline Right & Superior temporal sulcus & 9.52 & Fundus & 0.35 & 0.0005 & 15.000 & 3.125 & -6.250 \\
\hline Left & Basal forebrain & 7.32 & BST & 0.45 & 0.0076 & -0.625 & -1.875 & -1.875 \\
\hline Right & Premotor cortex & 7.08 & Area6 & 0.20 & 0.0307 & 23.125 & 0.000 & 11.250 \\
\hline
\end{tabular}

Voxelwise heritability analysis controlling for nuisance variation in age, age ${ }^{2}$, sex, and the age $\times$ sex interaction $\left(p<0.05\right.$, uncorrected, minimum cluster size of $7 \mathrm{~mm}{ }^{3}$ ). The regression was restricted to voxels demonstrating significant functional connectivity with the $\mathrm{Ce}(p<0.05$, whole-brain Šidák corrected) and significant relationships within individual differences in AT ( $p<0.005$, uncorrected).

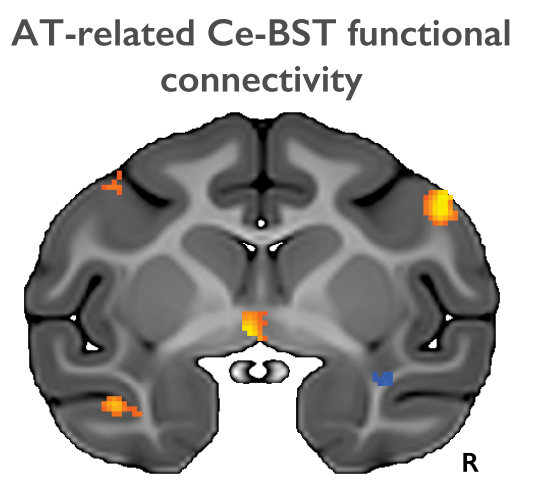

$-1.25 \mathrm{~mm}$

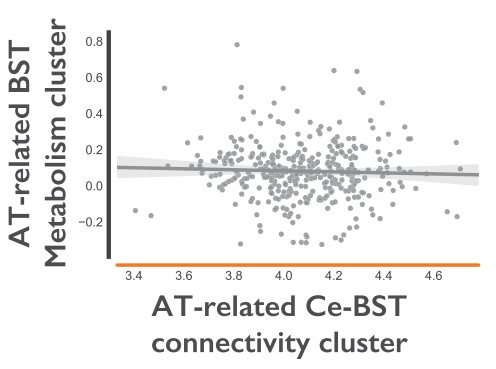

$r=-.038, p=.46$

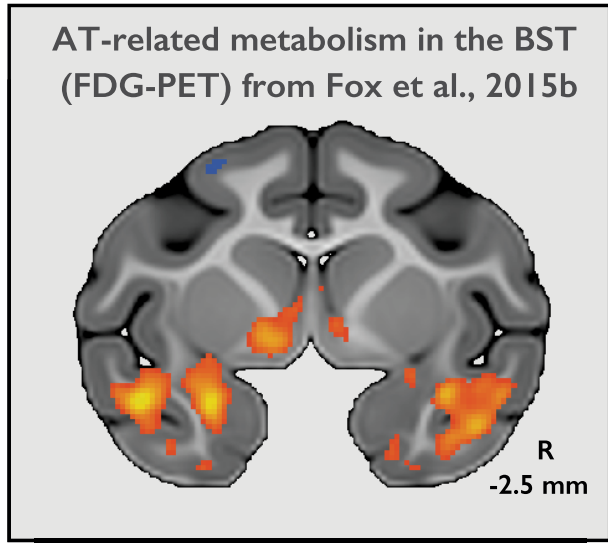

Figure 3. Within the same sample of animals, AT-related Ce connectivity in the BST (left) is essentially uncorrelated with AT-related metabolism in the BST (right), suggesting that these two neuroimaging signatures are mediated by different mechanisms.

ter previously identified by A. S. Fox et al. (2015b; Fig. 3, right). Because both Ce-BST functional connectivity and BST metabolism were genetically correlated with AT, and because we believe that Ce-BST functional connectivity is primarily driven by the dense anatomical projections from $\mathrm{Ce} \rightarrow \mathrm{BST}$, we hypothesized that functional connectivity between the Ce and BST would be associated with metabolism in the BST. Surprisingly, a regression analysis revealed that AT-related Ce connectivity and AT-related metabolism in the BST were essentially uncorrelated in this relatively large sample $(r=-0.038 ; p=0.46 ; 95 \%$ CI $[-0.138$, $0.063] ; n=378)$.

Although we do not know their underlying spatial confidence intervals (Ma et al., 1999), visual inspection of the data raises the possibility that the Ce-BST connectivity and BST metabolism clusters were anatomically non-overlapping. Considering that the BST is a functionally heterogeneous and anatomically complex region (Kim et al., 2013; A. S. Fox et al., 2015a; Gungor and Paré, 2016), an alternative explanation for the lack of correlation is that the two neuroimaging markers involve differing subdivisions of the BST. However, a cross-modality analysis yielded the same results when the Ce connectivity values were extracted from the BST cluster derived from the AT-related metabolism $(r=$ $-0.036 ; p=0.48 ; 95 \%$ CI $[-0.136,0.065])$, as well as when the metabolism data were extracted from the BST cluster defined by AT-related Ce connectivity $(r=0.047 ; p=0.36 ; 95 \%$ CI $[-0.054,0.147])$.

Considering our sample size $(n=378)$, we have $\sim 80 \%$ power to detect an association where Ce-BST functional connectivity predicted $2 \%$ of the variance in BST metabolism, $\sim 97 \%$ power to detect $4 \%$ variance explained, and $>99 \%$ power to detect $6 \%$ explained. Thus, rather than insufficient power to detect a relationship, it is likely that the observed lack of correlation between functional connectivity and FDG-PET reflects the fact that the two functional imaging modalities reflect disparate biological mechanisms. Although Ce-BST connectivity and BST metabo-
Table 3. Variance in AT accounted for by Ce-BST connectivity and BST metabolism

Total variance in AT accounted for by BST metabolism and Ce-BST connectivity $R^{2}=0.087$

$F=5.038$

$p=0.000018$

BST metabolism unique variance

$\Delta R^{2}=0.0302$

Ce-BST connectivity unique variance

$\Delta R^{2}=0.0383$

$\Delta F=12.219$

$p=0.000531$

Shared variance

$\Delta F=15.536$

$p=0.000097$

0.0023

lism are both genetically correlated with AT, the present results suggest that these markers are governed by distinct/dissociable genetic mechanisms. To clarify whether these markers are indeed additive and non-overlapping, we computed a hierarchical regression examining the extent to which Ce-BST connectivity and BST metabolism accounted for similar or non-overlapping variance in AT (Table 3). Results demonstrated that Ce-BST connectivity and BST metabolism account for mostly non-overlapping variance in AT (see Table 3; nuisance covariates were nonsignificant: $\left.R^{2}=0.016, p=0.293\right)$.

Finally, to discover other brain regions where metabolism mediates the influence of Ce-BST functional connectivity on AT, we conducted an exploratory cross-modality analysis focused on relationships between variation in Ce-BST connectivity and voxelwise FDG metabolism. This was restricted to regions where FDG was correlated with AT (A. S. Fox et al., 2015b). Intriguingly, this approach uncovered potential downstream targets of the EAc that may mediate the effects of coordinated Ce-BST fluctuations on AT. Results demonstrated that metabolism in several AT-related regions was significantly correlated with Ce-BST functional connectivity, including the hypothalamus and periaqueductal gray (PAG) (Fig. 4, Table 4). To understand how functional connectivity between the Ce and these regions relates to AT, we examined Ce connectivity with the PAG and hypothalamic regions. Ce connectivity with the PAG region defined in 
Regions showing significant relations between metabolism and AT (see Fox et al., 20I5b)

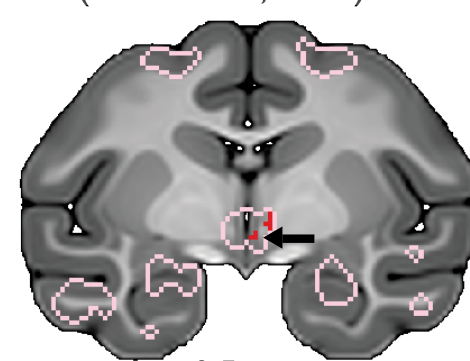

$2.5 \mathrm{~mm}$

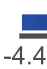

$-4.4$

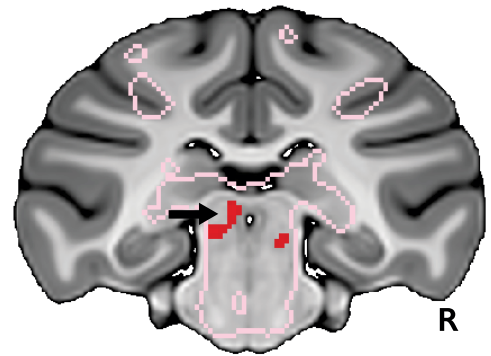

$15 \mathrm{~mm}$

2.2 t-value of Ce-BST connectivity related brain metabolism $(p<0.01$, uncorrected, two-tailed)

Figure 4. Stronger Ce-BST functional connectivity is associated with elevated FDG metabolism in the hypothalamus (left) and PAG (right). These regions are targets of both the Ce and the BST and are effector sites that mediate behavioral and neuroendocrine responses to threat. The pink outline indicates regions where variation in FDG metabolism is associated with elevated levels of AT ( $p<0.05$, whole-brain Šidák corrected, $n=592 ;$ A. S. Fox et al., 2015b).

this analysis (Fig. 4), was not significantly different from zero $(t=$ $-1.455 ; p=0.147)$. Ce connectivity with the hypothalamic region identified in the analysis (Fig. 4) was significantly different from zero $(t=3.411 ; p=0.001)$, and Ce-hypothalamic connectivity was correlated with Ce-BST connectivity $(t=4.203$; $p<$ 0.001). However, neither Ce-PAG connectivity nor Cehypothalamic connectivity was significantly correlated with AT, or any of its components $(p>0.05)$.

We performed a series of mediation analyses to examine the extent to which metabolism in the PAG and hypothalamic regions statistically explains the relationship between Ce-BST connectivity and AT. Results demonstrated that metabolic activity in the PAG (proportion mediated, $0.19 ; 95 \% \mathrm{CI}, 0.06-0.42 ; p=$ 0.0024 ) and in the hypothalamus (proportion mediated, 0.11 ; $95 \%$ CI, $0.02-0.29 ; p=0.0112$ ) significantly mediated relationships between Ce-BST connectivity and AT.

Finally, to explore whether these neural circuit elements reflect distinct aspects of the composite AT phenotype, we assessed relationships between regional FDG metabolism and Ce connectivity separately for measures of freezing, vocalizations, and cortisol. PAG metabolism was associated with AT, freezing, cooing, and cortisol $(p<0.05)$, and hypothalamic metabolism was associated with AT, freezing, and cooing $(p<0.05)$ but not cortisol $(p=0.12)$. Functional connectivity with the Ce was not associated with AT or any of its components in either the PAG or hypothalamus $(p>0.05)$.

\section{Discussion}

The present study leverages a unique combination of phenotypic and multimodal brain imaging data acquired from 378 members of an eight-generation pedigree of nearly 2000 rhesus monkeys to provide new insights into the neural and genetic bases of extreme dispositional anxiety, a prominent risk factor for the development of stress-related psychopathology (Clauss and Blackford, 2012; Fox and Kalin, 2014; Shackman et al., 2016a). Mechanistic and imaging work indicates that the Ce plays a critical role in early-life AT (Kalin et al., 2004; Oler et al., 2010, 2016), but the larger functional network in which the Ce is embedded and the subsystems most relevant to early-life AT remain unclear. The present results provide evidence of robust functional connectivity between the Ce and the BST, the two major divisions of the
4.4
EAc, reinforcing the hypothesis that they form a coherent functional unit (Alheid and Heimer, 1988; Oler et al., 2012; A. S. Fox et al., 2015a; Shackman and Fox, 2016; Fox and Shackman, 2017). This observation is consistent with prior fMRI studies in sedated monkeys (Oler et al., 2012, 2017; Birn et al., 2014) and quietly resting humans (Torrisi et al., 2015; Avery et al., 2016; Gorka et al., 2017; Tillman et al., 2018). Functional connectivity can reflect direct and/or multisynaptic structural connectivity (Honey et al., 2009; Adachi et al., 2012; Buckner et al., 2013; Birn et al., 2014). In this regard, the CeBST connectivity may reflect direct projections from the $\mathrm{Ce}$ to the $\mathrm{BST}$ $(\mathrm{Ce} \rightarrow \mathrm{BST})$ and/or bidirectional projections passing through the sublenticular extended amygdala (SLEA; $\mathrm{Ce} \leftrightarrow \mathrm{SLEA} \leftrightarrow$ BST; Heimer et al., 1999; Oler et al., 2017). It is also possible that the connectivity observed between Ce and BST stems from shared inputs to these structures, such as those ascending from the reciprocally connected PAG or from the basolateral amygdala. The present results extend our understanding of how interactions between the Ce and BST are related to anxiety and the high-risk AT phenotype.

\section{EAc and heritability of the AT phenotype}

The EAc is a continuum of neurons from the Ce to the BST, which has been hypothesized to be critical for mediating threat responses, and we previously demonstrated that metabolism in these structures is predictive of AT (Kalin et al., 2005; Oler et al., 2009, 2010; A. S. Fox et al., 2015a,b; Shackman and Fox, 2016). The present results extend work from our laboratory and others and further implicate the EAc in the early-life risk to develop anxiety and depressive disorders (Kalin et al., 2005; Oler et al., 2010; Fox and Kalin, 2014; A. S. Fox et al., 2015a; Avery et al., 2016; Shackman and Fox, 2016). Whereas prior research has demonstrated dissociable roles for the Ce and BST in fear and anxiety (Walker and Davis, 1997; Walker et al., 2009; Herrmann et al., 2016), the present data provide evidence that the interaction between these regions may be critical in understanding the neural activity that underlies dispositional anxiety.

Like anxiety disorders, AT and related constructs (e.g., childhood behavioral inhibition, neuroticism) reflect a combination of heritable and environmental factors (Fox and Kalin, 2014; A. S. Fox et al., 2015b; Shackman et al., 2016a). We previously determined that AT in young monkeys is $29 \%$ heritable, similar to heritability estimates for human anxiety and mood disorders (Hettema et al., 2005; Oler et al., 2010; A. S. Fox et al., 2015b) and heritability estimates for the presentation of early-life anxiety and behavioral inhibition (Emde et al., 1992; Eley et al., 2003). Here, we demonstrate for the first time that individual differences in the strength of functional connectivity between the Ce and BST are significantly heritable. Importantly, functional connectivity between the Ce and this same region of BST was also associated with higher levels of AT (Fig. 2). These results add to an emerging literature on the heritability of resting-state functional networks (Glahn et al., 2010; Colclough et al., 2017; Ge et al., 2017). In the current study, coheritability analyses demonstrated that Ce-BST functional connectivity and AT are passed down the family tree 
Table 4. Descriptive statistics for clusters showing significant relationships between Ce functional connectivity and AT-related brain metabolism

\begin{tabular}{|c|c|c|c|c|c|c|c|c|}
\hline \multirow[b]{2}{*}{ Hemisphere } & \multirow[b]{2}{*}{ Cluster } & \multirow[b]{2}{*}{ Volume $\left(\mathrm{mm}^{3}\right)$} & \multirow[b]{2}{*}{ Local maxima } & \multirow[b]{2}{*}{$t_{\mathrm{Max}}^{a}$} & \multirow[b]{2}{*}{$p$} & \multicolumn{3}{|c|}{ Location (mm from AC) } \\
\hline & & & & & & $x$ & $y$ & $Z$ \\
\hline Right & Anterior cingulate & 5.86 & Area $24 a$, genu of the corpus callosum & 3.07 & 0.0011 & 1.875 & -10.625 & 5.625 \\
\hline Left & Brainstem & 31.49 & Periaqueductal gray & 3.06 & 0.0012 & -2.500 & 14.375 & -0.625 \\
\hline Right & Thalamus & 3.17 & Ventral anterior nucleus & 2.88 & 0.0021 & 2.500 & 3.125 & -1.875 \\
\hline Right & Brainstem & 16.85 & Reticular formation, precuneiform & 2.83 & 0.0025 & 3.750 & 15.625 & -5.000 \\
\hline Left & Cerebellum & 1.95 & Deep cerebellar nuclei & 2.82 & 0.0025 & -5.625 & 24.375 & -11.250 \\
\hline Left & Hippocampus & 1.95 & Cornus ammonis & 2.82 & 0.0025 & -16.250 & 8.125 & -8.750 \\
\hline Right & Basal forebrain & 1.46 & Paraventricular nucleus, posterior medial BST & 2.64 & 0.0043 & 0.625 & 2.5 & -3.750 \\
\hline
\end{tabular}

${ }^{a}$ Voxelwise regression controlling for nuisance variation in mean-centered age, sex, and scanner site ( $p<0.01$, uncorrected, two-tailed, with no minimum cluster size). The regression was restricted to voxels where FDG metabolism was associated with higher levels of AT in our prior work ( $p<0.05$, whole-brain Šidák corrected, $n=592$; A. S. Fox et al., 2015b).

together $\left(\rho_{\mathrm{g}}=0.87\right)$, supporting the hypothesis that Ce-BST functional connectivity and AT share molecular underpinnings. Other work indicates that BST metabolism is also genetically correlated with AT (A. S. Fox et al., 2015b). Here, however, we show that BST metabolism and Ce-BST connectivity are unrelated, as each measure explains unique variance in AT, suggesting that the two imaging markers reflect dissociable mechanisms (Fig. 3, Table 3). This observation suggests that identifying the genetic basis of a singular, narrowly focused neural biomarker (e.g., BST metabolism) is likely to belie the functional and molecular heterogeneity within a region and be unlikely to fully explain the heritability of risk phenotypes or psychiatric diagnoses (Holmes and Patrick, 2018; Shackman and Fox, 2018).

\section{Potential mediators of EAc connectivity's effects on the AT phenotype}

Exploratory analyses revealed several regions of the brain where Ce-BST connectivity and metabolism were positively associated, including the PAG (Fig. 4). This finding is intriguing because the PAG is the recipient of parallel anatomical projections from the Ce and the BST (Nagy and Paré, 2008). Although we did not observe AT-related intrinsic functional connectivity between the Ce and either PAG or hypothalamus, metabolism in these regions partially mediated relationships between Ce-BST functional connectivity and AT. Thus, it is plausible that the coordination of activity between the Ce and BST affects AT by changing the metabolism of shared downstream targets, such as the PAG.

The PAG is of particular interest because it is a component of the AT network in nonhuman primates (A. S. Fox et al., 2015b), and mechanistic work in rodent models indicates that it plays a critical role in organizing threat-related freezing (Tovote et al., 2016; Kim et al., 2017), a core component of the AT phenotype (Fox et al., 2008; Shackman et al., 2013). Although this observation is broadly consistent with prior work implicating the PAG in the control of fear and anxiety (Carrive and Morgan, 2012; Assareh et al., 2016; Motta et al., 2017), it will be important to replicate this preliminary discovery and assess it using mechanistic interventions in nonhuman primates. More generally, these data raise the possibility that functional coordination between regions is associated with metabolic differences in their shared downstream projections, perhaps because of an increased likelihood of signals from the two regions simultaneously depolarizing neurons in their shared effector site.

\section{Future challenges}

A number of important challenges remain. As with most brain imaging studies, our analyses do not permit mechanistic inferences. Like other studies focused on functional connectivity, our conclusions are tempered by questions about the origins and significance of correlated fluctuations in the BOLD fMRI (Logo- thetis, 2008). A key challenge for future research will be to use a combination of mechanistic (e.g., chemogenetic) and wholebrain imaging techniques to clarify the causal contributions of the regions highlighted here to more precisely delineate the nature of their functional interactions (Shackman and Fox, 2016; Wiegert et al., 2017; Fox and Shackman, 2017). It will also be useful to test whether existing anxiolytic compounds normalize Ce-BST functional connectivity. If so, then this biomarker could potentially be used to evaluate novel therapeutics (Borsook et al., 2006; Bullmore, 2012; Woo et al., 2017). Also, and for further study, it would be useful to examine relationships between taskrelated assessments of Ce-BST connectivity and AT. Assessment of connectivity under conditions of potential threat could be more predictive of AT (Buff et al., 2017; Lange et al., 2017; Brinkmann et al., 2018; Torrisi et al., 2018). Future work examining model-based effective connectivity during periods of threat processing is likely to implicate specific patterns of neural information processing throughout the brain systems that underlie AT and further elucidate the role of the EAc in AT. Finally, it will be important to evaluate whether these discoveries in the rhesus monkey translate to children with extreme anxiety.

Although the use of a relatively large sample enhances confidence in the robustness of these results and the precision of the accompanying effect-size estimates (Schönbrodt and Perugini, 2013; Poldrack et al., 2017; Fox et al., 2018), the statistically significant behavioral effects are modest in size, consistent with other recent large-scale studies of temperament-outcome (Moffitt et al., 2011; Jeronimus et al., 2016) and brain-behavior relationships (Whelan et al., 2014; A. S. Fox et al., 2015b; Swartz et al., 2015; Kaczkurkin et al., 2016), a point emphasized by other recent commentators (Holmes and Patrick, 2018; Shackman and Fox, 2018). In particular, Ce-BST functional connectivity statistically explains a relatively small amount of variation in the AT phenotype. This is not altogether surprising given the known complexity of the neural circuitry underlying individual differences in AT, which encompasses microcircuits within the EAc and macrocircuits extending well beyond the EAc to include interactions with the dorsolateral prefrontal cortex, orbitofrontal cortex/anterior insula, anterior hippocampus, thalamus, PAG, and other regions (Shackman et al., 2016a; Fox and Shackman, 2017). The data described here highlight the utility of multimodal brain imaging for identifying potentially different mechanisms within the same region that mediate the relationship between genes and behavior. That FDG-PET-measured BST metabolism and fMRI-measured Ce-BST connectivity are independently associated with a heritable component of AT suggests the need to consider independent genetic contributions to metabolism and connectivity within the EAc, and presumably elsewhere in the brain. Understanding the genetic basis of one disorder-related intermedi- 
ate phenotype is likely to be insufficient to fully explain the heritability of the high-risk AT phenotype or anxiety disorders.

\section{Conclusions}

Understanding the early-life alterations in the neural circuitry that underlies the childhood risk to develop anxiety disorders provides an opportunity to conceptualize novel interventions aimed at prevention. Furthermore, existing treatments for anxiety disorders need to be improved as they are often ineffective, are focused on symptoms rather than pathophysiology, and can be associated with adverse side effects (Bystritsky, 2006; Cloos and Ferreira, 2009; James et al., 2015; Cuijpers et al., 2016; Craske et al., 2017). These data provide insights into the complexities involving the targeting of specific brain regions as therapeutic strategies. Within the EAc, this work demonstrates distinct ATrelated mechanisms that are indexed by functional connectivity and metabolism and likely reflect different pathophysiological processes. These data suggest that treatments targeting a change within a single modality are likely to be suboptimal and that different treatments are likely be required to effect change in different pathophysiologies, even those identified within the same brain region. Additionally, these data support the potential use of measures assessing EAc function in the characterization of novel pharmacological, psychological and behavioral approaches for the treatment of anxiety and stress-related psychopathology.

\section{References}

Acosta-Cabronero J, Williams GB, Pereira JM, Pengas G, Nestor PJ (2008) The impact of skull-stripping and radio-frequency bias correction on grey-matter segmentation for voxel-based morphometry. Neuroimage 39:1654-1665. CrossRef Medline

Adachi Y, Osada T, Sporns O, Watanabe T, Matsui T, Miyamoto K, Miyashita Y (2012) Functional connectivity between anatomically unconnected areas is shaped by collective network-level effects in the macaque cortex. Cereb Cortex 22:1586-1592. CrossRef Medline

Alheid GF, Heimer L (1988) New perspectives in basal forebrain organization of special relevance for neuropsychiatric disorders: the striatopallidal, amygdaloid, and corticopetal components of substantia innominata. Neuroscience 27:1-39. CrossRef Medline

Almasy L, Blangero J (1998) Multipoint quantitative-trait linkage analysis in general pedigrees. Am J Hum Genet 62:1198-1211. CrossRef Medline

Almasy L, Dyer TD, Blangero J (1997) Bivariate quantitative trait linkage analysis: pleiotropy versus co-incident linkages. Genet Epidemiol 14:953958. CrossRef Medline

Amaral DG, Price JL, Pitkänen A, Carmichael ST (1992) Anatomical organization of the primate amygdaloid complex. In: The amygdala: neurobiological aspects of emotion, memory, and mental dysfunction (Aggelton JP, ed), pp 1-66. New York, NY: Wiley.

Assareh N, Sarrami M, Carrive P, McNally GP (2016) The organization of defensive behavior elicited by optogenetic excitation of rat lateral or ventrolateral periaqueductal gray. Behav Neurosci 130:406-414. CrossRef Medline

Avants BB, Yushkevich P, Pluta J, Minkoff D, Korczykowski M, Detre J, Gee JC (2010) The optimal template effect in hippocampus studies of diseased populations. Neuroimage 49:2457-2466. CrossRef Medline

Avants BB, Tustison NJ, Song G, Cook PA, Klein A, Gee JC (2011) A reproducible evaluation of ANTs similarity metric performance in brain image registration. Neuroimage 54:2033-2044. CrossRef Medline

Avery SN, Clauss JA, Blackford JU (2016) The human BNST: functional role in anxiety and addiction. Neuropsychopharmacology 41:126-141. CrossRef Medline

Bauers KA, de Waal FBM (1991) "Coo" vocalizations in stumptailed macaques: a controlled functional analysis. Behaviour 119:143-160. CrossRef

Borsook D, Becerra L, Hargreaves R (2006) A role for fMRI in optimizing CNS drug development. Nat Rev Drug Discov 5:411-424. CrossRef Medline

Brinkmann L, Buff C, Feldker K, Neumeister P, Heitmann CY, Hofmann D, Bruchmann M, Herrmann MJ, Straube T (2018) Inter-individual differences in trait anxiety shape the functional connectivity between the bed nucleus of the stria terminalis and the amygdala during brief threat processing. Neuroimage 166:110-116. CrossRef Medline

Buckner RL, Krienen FM, Yeo BT (2013) Opportunities and limitations of intrinsic functional connectivity MRI. Nat Neurosci 16:832-837. CrossRef Medline

Buff C, Brinkmann L, Bruchmann M, Becker MPI, Tupak S, Herrmann MJ, Straube T (2017) Activity alterations in the bed nucleus of the stria terminalis and amygdala during threat anticipation in generalized anxiety disorder. Soc Cogn Affect Neurosci 12:1766-1774. CrossRef Medline

Bullmore E (2012) The future of functional MRI in clinical medicine. Neuroimage 62:1267-1271. CrossRef Medline

Bystritsky A (2006) Treatment-resistant anxiety disorders. Mol Psychiatry 11:805-814. CrossRef Medline

Carrive P, Morgan MM (2012) Periaqueductal gray. In: The human nervous system, Ed 3 (Mai JK, Paxinos G, eds), pp 367-400. New York, NY: Academic.

Christian BT, Fox AS, Oler JA, Vandehey NT, Murali D, Rogers J, Oakes TR, Shelton SE, Davidson RJ, Kalin NH (2009) Serotonin transporter binding and genotype in the nonhuman primate brain using [C-11]DASB PET. Neuroimage 47:1230-1236. CrossRef Medline

Clauss JA, Blackford JU (2012) Behavioral inhibition and risk for developing social anxiety disorder: a meta-analytic study. J Am Acad Child Adolesc Psychiatry 51:1066-1075.e1. Medline

Cloos JM, Ferreira V (2009) Current use of benzodiazepines in anxiety disorders. Curr Opin Psychiatry 22:90-95. CrossRef Medline

Colclough GL, Smith SM, Nichols TE, Winkler AM, Sotiropoulos SN, Glasser MF, Van Essen DC, Woolrich MW (2017) The heritability of multimodal connectivity in human brain activity. Elife 6:e20178. CrossRef Medline

Cox RW (1996) AFNI: software for analysis and visualization of functional magnetic resonance neuroimages. Comput Biomed Res 29:162-173. CrossRef Medline

Craske MG, Stein MB, Eley TC, Milad MR, Holmes A, Rapee RM, Wittchen HU (2017) Anxiety disorders. Nat Rev Dis Primers 3:17024. CrossRef Medline

Cuijpers P, Cristea IA, Karyotaki E, Reijnders M, Huibers MJ (2016) How effective are cognitive behavior therapies for major depression and anxiety disorders? A meta-analytic update of the evidence. World Psychiatry 15:245-258. CrossRef Medline

DiLalla LF, Kagan J, Reznick JS (1994) Genetic etiology of behavioral inhibition among 2-year-old children. Infant Behav Dev 17:405-412. CrossRef

Eley TC, Bolton D, O'Connor TG, Perrin S, Smith P, Plomin R (2003) A twin study of anxiety-related behaviours in pre-school children. J Child Psychol Psychiatry 44:945-960. CrossRef Medline

Emde RN, Plomin R, Robinson JA, Corley R, DeFries J, Fulker DW, Reznick JS, Campos J, Kagan J, Zahn-Waxler C (1992) Temperament, emotion, and cognition at fourteen months: the MacArthur longitudinal twin study. Child Dev 63:1437-1455. CrossRef Medline

Fein G, Landman B, Tran H, Barakos J, Moon K, Di Sclafani V, Shumway R (2006) Statistical parametric mapping of brain morphology: sensitivity is dramatically increased by using brain-extracted images as inputs. Neuroimage 30:1187-1195. CrossRef Medline

Fischmeister FP, Höllinger I, Klinger N, Geissler A, Wurnig MC, Matt E, Rath J, Robinson SD, Trattnig S, Beisteiner R (2013) The benefits of skull stripping in the normalization of clinical fMRI data. Neuroimage Clin 3:369-380. CrossRef Medline

Fox AS, Kalin NH (2014) A translational neuroscience approach to understanding the development of social anxiety disorder and its pathophysiology. Am J Psychiatry 171:1162-1173. CrossRef Medline

Fox AS, Shackman AJ (2017) The central extended amygdala in fear and anxiety: closing the gap between mechanistic and neuroimaging research. Neurosci Lett. Advance online publication. Retrieved November 30, 2017. doi:10.1016/j.neulet.2017.11.056.

Fox AS, Oakes TR, Shelton SE, Converse AK, Davidson RJ, Kalin NH (2005) Calling for help is independently modulated by brain systems underlying goal-directed behavior and threat perception. Proc Natl Acad Sci U S A 102:4176-4179. CrossRef Medline

Fox AS, Shelton SE, Oakes TR, Davidson RJ, Kalin NH (2008) Trait-like brain activity during adolescence predicts anxious temperament in primates. PLoS One 3:e2570. CrossRef Medline

Fox AS, Oler JA, Tromp do PM, Fudge JL, Kalin NH (2015a) Extending the 
amygdala in theories of threat processing. Trends Neurosci 38:319-329. CrossRef Medline

Fox AS, Oler JA, Shackman AJ, Shelton SE, Raveendran M, McKay DR, Converse AK, Alexander A, Davidson RJ, Blangero J, Rogers J, Kalin NH (2015b) Intergenerational neural mediators of early-life anxious temperament. Proc Natl Acad Sci U S A 112:9118-9122. CrossRef Medline

Fox AS, Lapate RC, Davidson RJ, Shackman AJ (2018) The nature of emotion: a research agenda for the 21st century. In: The nature of emotion. Fundamental questions., Ed 2 (Fox AS, Lapate RC, Shackman AJ, Davidson RJ, eds). New York, NY: Oxford.

Fox NA, Henderson HA, Marshall PJ, Nichols KE, Ghera MM (2005) Behavioral inhibition: linking biology and behavior within a developmental framework. Annu Rev Psychol 56:235-262. CrossRef Medline

Freese JL, Amaral DG (2009) Neuroanatomy of the primate amygdala. In: The human amygdala (Whalen PJ, Phelps EA, eds), pp 3-42. New York, NY: Guilford.

Ge T, Holmes AJ, Buckner RL, Smoller JW, Sabuncu MR (2017) Heritability analysis with repeat measurements and its application to resting-state functional connectivity. Proc Natl Acad Sci U S A 114:5521-5526. CrossRef Medline

Geschwind DH, Flint J (2015) Genetics and genomics of psychiatric disease. Science 349:1489-1494. CrossRef Medline

Glahn DC, Winkler AM, Kochunov P, Almasy L, Duggirala R, Carless MA, Curran JC, Olvera RL, Laird AR, Smith SM, Beckmann CF, Fox PT, Blangero J (2010) Genetic control over the resting brain. Proc Natl Acad Sci U S A 107:1223-1228. CrossRef Medline

Glover GH, Li TQ, Ress D (2000) Image-based method for retrospective correction of physiological motion effects in fMRI: RETROICOR. Magn Reson Med 44:162-167. CrossRef Medline

Gorka AX, Torrisi S, Shackman AJ, Grillon C, Ernst M (2017) Intrinsic functional connectivity of the central nucleus of the amygdala and bed nucleus of the stria terminalis. Neuroimage 168:392-402. CrossRef Medline

Gungor NZ, Paré D (2016) Functional heterogeneity in the bed nucleus of the stria terminalis. J Neurosci 36:8038-8049. CrossRef Medline

Heimer L, De Olmos JS, Alheid GF, Person J, Sakamoto N, Shinoda K, Marksteiner J, Switzer RC (1999) The human basal forebrain. Part II. In: Handbook of chemical Neuroanatomy (Bloom FE, Bjorkland A, Hokfelt T, eds), pp 57-226. Amsterdam, the Netherlands: Elsevier.

Heimer L, Van Hoesen GW (2006) The limbic lobe and its output channels: implications for emotional functions and adaptive behavior. Neurosci Biobehav Rev 30:126-147. CrossRef Medline

Herrmann MJ, Boehme S, Becker MP, Tupak SV, Guhn A, Schmidt B, Brinkmann L, Straube T (2016) Phasic and sustained brain responses in the amygdala and the bed nucleus of the stria terminalis during threat anticipation. Hum Brain Mapp 37:1091-1102. CrossRef Medline

Hettema JM, Prescott CA, Myers JM, Neale MC, Kendler KS (2005) The structure of genetic and environmental risk factors for anxiety disorders in men and women. Arch Gen Psychiatry 62:182-189. CrossRef Medline

Hirshfeld-Becker DR, Micco J, Henin A, Bloomfield A, Biederman J, Rosenbaum J (2008) Behavioral inhibition. Depress Anxiety 25:357-367. CrossRef Medline

Holmes AJ, Patrick LM (2018) The myth of optimality in clinical neuroscience. Trends Cogn Sci 22:241-257. CrossRef Medline

Honey CJ, Sporns O, Cammoun L, Gigandet X, Thiran JP, Meuli R, Hagmann P (2009) Predicting human resting-state functional connectivity from structural connectivity. Proc Natl Acad Sci U S A 106:2035-2040. CrossRef Medline

Imai K, Keele L, Tingley D (2010) A general approach to causal mediation analysis. Psychol Methods 15:309-334. CrossRef Medline

Jahn AL, Fox AS, Abercrombie HC, Shelton SE, Oakes TR, Davidson RJ, Kalin NH (2010) Subgenual prefrontal cortex activity predicts individual differences in hypothalamic-pituitary-adrenal activity across different contexts. Biol Psychiatry 67:175-181. CrossRef Medline

James AC, James G, Cowdrey FA, Soler A, Choke A (2015) Cognitive behavioural therapy for anxiety disorders in children and adolescents. Cochrane Database Syst Rev CD004690. CrossRef Medline

Jeronimus BF, Kotov R, Riese H, Ormel J (2016) Neuroticism's prospective association with mental disorders halves after adjustment for baseline symptoms and psychiatric history, but the adjusted association hardly decays with time: a meta-analysis on 59 longitudinal/prospective studies with 443313 participants. Psychol Med 46:2883-2906. CrossRef Medline
Jo HJ, Saad ZS, Simmons WK, Milbury LA, Cox RW (2010) Mapping sources of correlation in resting state FMRI, with artifact detection and removal. Neuroimage 52:571-582. CrossRef Medline

Kaczkurkin AN, Moore TM, Ruparel K, Ciric R, Calkins ME, Shinohara RT, Elliott MA, Hopson R, Roalf DR, Vandekar SN, Gennatas ED, Wolf DH, Scott JC, Pine DS, Leibenluft E, Detre JA, Foa EB, Gur RE, Gur RC, Satterthwaite TD (2016) Elevated amygdala perfusion mediates developmental sex differences in trait anxiety. Biol Psychiatry 80:775-785. CrossRef Medline

Kagan J (1997) Galen's prophecy: Temperament in human nature. New York, NY: Perseus.

Kagan J, Reznick JS, Snidman N (1987) The physiology and psychology of behavioral inhibition in children. Child Dev 58:1459-1473. CrossRef Medline

Kagan J, Reznick JS, Snidman N (1988) Biological bases of childhood shyness. Science 240:167-171. CrossRef Medline

Kalin NH (1993) The neurobiology of fear. Sci Am 268:94-101. Medline

Kalin NH (2017) Mechanisms underlying the early risk to develop anxiety and depression: a translational approach. Eur Neuropsychopharmacol 27:543-553. CrossRef Medline

Kalin NH, Shelton SE (1989) Defensive behaviors in infant rhesus monkeys: environmental cues and neurochemical regulation. Science 243:17181721. CrossRef Medline

Kalin NH, Shelton SE (1998) Ontogeny and stability of separation and threat-induced defensive behaviors in rhesus monkeys during the first year of life. Am J Primatol 44:125-135. CrossRef Medline

Kalin NH, Shelton SE (2003) Nonhuman primate models to study anxiety, emotion regulation, and psychopathology. Ann N Y Acad Sci 1008:189200. CrossRef Medline

Kalin NH, Shelton SE, Rickman M, Davidson RJ (1998) Individual differences in freezing and cortisol in infant and mother rhesus monkeys. Behav Neurosci 112:251-254. CrossRef Medline

Kalin NH, Shelton SE, Davidson RJ (2004) The role of the central nucleus of the amygdala in mediating fear and anxiety in the primate. J Neurosci 24:5506-5515. CrossRef Medline

Kalin NH, Shelton SE, Fox AS, Oakes TR, Davidson RJ (2005) Brain regions associated with the expression and contextual regulation of anxiety in primates. Biol Psychiatry 58:796-804. CrossRef Medline

Kalin NH, Fox AS, Kovner R, Riedel MK, Fekete EM, Roseboom PH, Tromp DP, Grabow BP, Olsen ME, Brodsky EK, McFarlin DR, Alexander AL, Emborg ME, Block WF, Fudge JL, Oler JA (2016) Overexpressing corticotropin-releasing hormone in the primate amygdala increases anxious temperament and alters its neural circuit. Biol Psychiatry 80:345355. CrossRef Medline

Kim CK, Adhikari A, Deisseroth K (2017) Integration of optogenetics with complementary methodologies in systems neuroscience. Nat Rev Neurosci 18:222-235. CrossRef Medline

Kim SY, Adhikari A, Lee SY, Marshel JH, Kim CK, Mallory CS, Lo M, Pak S, Mattis J, Lim BK, Malenka RC, Warden MR, Neve R, Tye KM, Deisseroth K (2013) Diverging neural pathways assemble a behavioural state from separable features in anxiety. Nature 496:219-223. CrossRef Medline

LaBar KS, Gitelman DR, Mesulam MM, Parrish TB (2001) Impact of signalto-noise on functional MRI of the human amygdala. Neuroreport 12: 3461-3464. CrossRef Medline

Lange MD, Daldrup T, Remmers F, Szkudlarek HJ, Lesting J, Guggenhuber S, Ruehle S, JünglingK, Seidenbecher T, Lutz B, Pape HC (2017) Cannabinoid $\mathrm{CB} 1$ receptors in distinct circuits of the extended amygdala determine fear responsiveness to unpredictable threat. Molecular psychiatry 22:1422-1430. CrossRef Medline

Logothetis NK (2008) What we can do and what we cannot do with fMRI. Nature 453:869-878. CrossRef Medline

Ma L, Worsley KJ, Evans AC (1999) Variability of spatial location of activation in fMRI and PET CBF images. Neuroimage 9:S178.

Moffitt TE, Arseneault L, Belsky D, Dickson N, Hancox RJ, Harrington H, Houts R, Poulton R, Roberts BW, Ross S, Sears MR, Thomson WM, Caspi A (2011) A gradient of childhood self-control predicts health, wealth, and public safety. Proc Natl Acad Sci U S A 108:2693-2698. CrossRef Medline

Motta SC, Carobrez AP, Canteras NS (2017) The periaqueductal gray and primal emotional processing critical to influence complex defensive responses, fear learning and reward seeking. Neurosci Biobehav Rev 76:3947. CrossRef Medline 
Nagy FZ, ParéD (2008) Timing of impulses from the central amygdala and bed nucleus of the stria terminalis to the brain stem. J Neurophysiol 100:3429-3436. CrossRef Medline

Oler JA, Fox AS, Shelton SE, Christian BT, Murali D, Oakes TR, Davidson RJ, Kalin NH (2009) Serotonin transporter availability in the amygdala and bed nucleus of the stria terminalis predicts anxious temperament and brain glucose metabolic activity. J Neurosci 29:9961-9966. CrossRef Medline

Oler JA, Fox AS, Shelton SE, Rogers J, Dyer TD, Davidson RJ, Shelledy W, Oakes TR, Blangero J, Kalin NH (2010) Amygdalar and hippocampal substrates of anxious temperament differ in their heritability. Nature 466: 864-868. CrossRef Medline

Oler JA, Birn RM, Patriat R, Fox AS, Shelton SE, Burghy CA, Stodola DE, Essex MJ, Davidson RJ, Kalin NH (2012) Evidence for coordinated functional activity within the extended amygdala of non-human and human primates. Neuroimage 61:1059-1066. CrossRef Medline

Oler JA, Fox AS, Shackman AJ, Kalin NH (2016) The central nucleus of the amygdala is a critical substrate for individual differences in anxiety. In: Living without an amygdala (Amaral DG, Adolphs R, eds), pp 218-251. New York, NY: Guilford.

Oler JA, Tromp DP, Fox AS, Kovner R, Davidson RJ, Alexander AL, McFarlin DR, Birn RM, Berg EB, deCampo DM, Kalin NH, Fudge JL (2017) Connectivity between the central nucleus of the amygdala and the bed nucleus of the stria terminalis in the non-human primate: neuronal tract tracing and developmental neuroimaging studies. Brain Struct Funct 222:21-39. CrossRef Medline

O’Rourke H, Fudge JL (2006) Distribution of serotonin transporter labeled fibers in amygdaloid subregions: implications for mood disorders. Biol Psychiatry 60:479-490. CrossRef Medline

Parrish TB, Gitelman DR, LaBar KS, Mesulam MM (2000) Impact of signalto-noise on functional MRI. Magn Reson Med 44:925-932. CrossRef Medline

Paxinos G, Huang X, Petrides M, Toga A (2009) The rhesus monkey brain in stereotaxic coordinates, Ed 2. San Diego, CA: Academic.

Poldrack RA, Baker CI, Durnez J, Gorgolewski KJ, Matthews PM, Munafò MR, Nichols TE, Poline JB, Vul E, Yarkoni T (2017) Scanning the horizon: towards transparent and reproducible neuroimaging research. Nat Rev Neurosci 18:115-126. CrossRef Medline

Rawlins RG, Kessler MJ (1986) Demography of the free-ranging Cayo Santiago macaques (1976-1983). In: The Cayo Santiago macaques. History, behavior, and biology (Rawlins RG, Kessler MJ, eds), pp 47-72. Albany, NY: SUNY.

Saad ZS, Glen DR, Chen G, Beauchamp MS, Desai R, Cox RW (2009) A new method for improving functional-to-structural MRI alignment using local Pearson correlation. Neuroimage 44:839-848. CrossRef Medline

Schönbrodt FD, Perugini M (2013) At what sample size do correlations stabilize? J Res Personality 47:609-612. CrossRef

Shackman AJ, Fox AS (2016) Contributions of the central extended amygdala to fear and anxiety. J Neurosci 36:8050-8063. CrossRef Medline

Shackman AJ, Fox AS (2018) Getting serious about variation: lessons for clinical neuroscience (a commentary on "The myth of optimality in clinical neuroscience"). Trends Cogn Sci 22:368-369. CrossRef Medline

Shackman AJ, Fox AS, Oler JA, Shelton SE, Davidson RJ, Kalin NH (2013) Neural mechanisms underlying heterogeneity in the presentation of anxious temperament. Proc Natl Acad Sci U S A 110:6145-6150. CrossRef Medline

Shackman AJ, Fox AS, Oler JA, Shelton SE, Oakes TR, Davidson RJ, Kalin NH
(2017) Heightened extended amygdala metabolism following threat characterizes the early phenotypic risk to develop anxiety-related psychopathology. Mol Psychiatry 22:724-732. CrossRef Medline

Shackman AJ, Tromp DP, Stockbridge MD, Kaplan CM, Tillman RM, Fox AS (2016a) Dispositional negativity: An integrative psychological and neurobiological perspective. Psychol Bull 142:1275-1314. CrossRef Medline

Shackman AJ, Stockbridge MD, Tillman RM, Kaplan CM, Tromp DP, Fox AS, Gamer M (2016b) The neurobiology of dispositional negativity and attentional biases to threat: implications for understanding anxiety disorders in adults and youth. J Exp Psychopathol 7:311-342. Medline

Swartz JR, Knodt AR, Radtke SR, Hariri AR (2015) A neural biomarker of psychological vulnerability to future life stress. Neuron 85:505-511. CrossRef Medline

Tai C, Chatziioannou A, Siegel S, Young J, Newport D, Goble RN, Nutt RE, Cherry SR (2001) Performance evaluation of the microPET P4: a PET system dedicated to animal imaging. Phys Med Biol 46:1845-1862. CrossRef Medline

Tillman RM, Stockbridge MD, Nacewicz BM, Torrisi S, Fox AS, Smith JF, Shackman AJ (2018) Intrinsic functional connectivity of the central extended amygdala. Hum Brain Mapp 39:1291-1312. CrossRef Medline

Tingley D, Yamamoto T, Hirose K, Keele L, Imai K (2014) Mediation: r package for causal mediation analysis. J Statist Softw 1:2014.

Torrisi S, O'Connell K, Davis A, Reynolds R, Balderston N, Fudge JL, Grillon C, Ernst M (2015) Resting state connectivity of the bed nucleus of the stria terminalis at ultra-high field. Hum Brain Mapp 36:4076-4088. CrossRef Medline

Torrisi S, Gorka AX, Gonzalez-Castillo J, O’Connell K, Balderston N, Grillon C, Ernst M (2018) Extended amygdala connectivity changes during sustained shock anticipation. Transl Psychiatry 8:33. CrossRef Medline

Tovote P, Esposito MS, Botta P, Chaudun F, Fadok JP, Markovic M, Wolff SB, Ramakrishnan C, Fenno L, Deisseroth K, Herry C, Arber S, LüthiA (2016) Midbrain circuits for defensive behaviour. Nature 534:206-212. CrossRef Medline

Walker DL, Davis M (1997) Double dissociation between the involvement of the bed nucleus of the stria terminalis and the central nucleus of the amygdala in startle increases produced by conditioned versus unconditioned fear. J Neurosci 17:9375-9383. CrossRef Medline

Walker DL, Miles LA, Davis M (2009) Selective participation of the bed nucleus of the stria terminalis and CRF in sustained anxiety-like versus phasic fear-like responses. Prog Neuropsychopharmacol Biol Psychiatry 33:1291-1308. CrossRef Medline

Whelan R, Watts R, Orr CA, Althoff RR, Artiges E, Banaschewski T, Barker GJ, Bokde AL, Büchel C, Carvalho FM, Conrod PJ, Flor H, Fauth-Bühler M, Frouin V, Gallinat J, Gan G, Gowland P, Heinz A, Ittermann B, Lawrence C, et al. (2014) Neuropsychosocial profiles of current and future adolescent alcohol misusers. Nature 512:185-189. CrossRef Medline

Wiegert JS, Mahn M, Prigge M, Printz Y, Yizhar O (2017) Silencing neurons: tools, applications, and experimental constraints. Neuron 95:504529. CrossRef Medline

Williams JT, Van Eerdewegh P, Almasy L, Blangero J (1999) Joint multipoint linkage analysis of multivariate qualitative and quantitative traits. I. Likelihood formulation and simulation results. Am J Hum Genet 65:1134-1147. CrossRef Medline

Woo CW, Chang LJ, Lindquist MA, Wager TD (2017) Building better biomarkers: brain models in translational neuroimaging. Nat Neurosci 20: 365-377. CrossRef Medline 